\title{
Transplante de córnea com uso inadvertido de córnea de doador previamente submetido à cirurgia refrativa - Relato de caso
}

\author{
Corneal transplant utilizing a cornealgraft that had undergonelaser surgery-Case report
}

Roberta Jansen de Mello Farias ${ }^{1}$

André Parolim ${ }^{2}$

Luciene Barbosa de Sousa ${ }^{3}$

\section{RESUMO}

Relato de caso de paciente atendido no Departamento de Córnea do Hospital Oftalmológico de Sorocaba e submetido a transplante penetrante de córnea para correção de ceratocone no olho esquerdo. Foi utilizada córnea doadora previamente submetida a LASIK. A cirurgia foi completada sem intercorrências, embora durante $\mathrm{o}$ ato cirúrgico o cirurgião tenha percebido que havia um "flap" no botão doador. O paciente está no 60 mês pós-operatório com visão de 20/40 com correção. OPAM era de 20/40. Há epitélio na interface superior do "flap" sem sinais de progressão. Devemse procurar novos métodos de avaliação de córneas doadoras; a utilização inadvertida de córnea doadora submetida a LASIK não interferiu até o $6^{0}$ mês pós-operatório no resultado final do transplante; acompanhamento prolongado é necessário para avaliar a transparência e evolução da ceratometria e erro refracional deste transplante a longo prazo.

Descritores: Ceratoplastia penetrante; Ceratocone/cirurgia; Transplante de córnea Refração ocular; Cirurgia a laser; Relatos de casos [Tipo de publicação]

\section{INTRODUÇ̃̃̃O}

Segundo dados do Ministério da Saúde, foram realizados 1.819 transplantes de córnea pelo Sistema Único de Saúde (SUS) em 1997 enquanto em 2003 foram realizados 3.683 transplantes, o que representou um crescimento de $102,5 \%$ no número de transplantes de córnea realizados no país ${ }^{(1)}$.

No Brasil são realizadas cerca de 199.678 cirurgias refrativas por ano ${ }^{(2)}$, enquanto cerca de 200.000 americanos são submetidos a alguma forma de cirurgia refrativa anualmente ${ }^{(3)}$. A cirurgia refrativa em geral é realizada em pacientes entre 20-60 anos de idade, sendo esta faixa etária responsável por $25 \%$ das doações de córneas recebidas no Canadá(4).

Com o aumento do número de procedimentos refrativos no mundo, é de se esperar que os oftalmologistas se defrontem com córneas doadoras previamente submetidas a cirurgias de LASIK (laser assisted in situ keratomileusis), LASEK (laser assisted epithelial keratectomy) ou PRK (photorefractive keratectomy).

Relatamos um caso de transplante de córnea penetrante (TP) utilizando, inadvertidamente, córnea de paciente previamente submetido à cirurgia de LASIK.

\section{DESCRIĈ̃̃ DE CASO CLÍNICO}

GRC, 35 anos, portador de ceratocone no olho esquerdo (OE). Já havia 
feito transplante de córnea no olho direito (OD) há 8 anos. Apresentava acuidade visual (AV) com correção inicial de 20/25p no OD e CD 2m no OE. Com ceratometria OE 48,51 X 58,19 não mais conseguia adaptar lente de contato. $\mathrm{O}$ fundo de olho esquerdo não apresentava alterações. Foi inscrito para transplante córnea, tendo sido submetido à cirurgia 7 meses após.

O botão direito utilizado foi recebido de um doador de 46 anos, masculino e classificado como sendo bom pelos critérios de avaliação do Banco de Olhos. O paciente faleceu por insuficiência respiratória secundária a neoplasia de pâncreas e os parentes desconheciam relatos de cirurgia oftalmológica, não havendo assim, contra-indicações a doação de córneas. As sorologias para HIV (Human immunodeficiency virus) e HbsAg (Hepatitis B superficial antigen) foram negativas. O epitélio era íntegro, com edema estromal leve e contagem de células de $2724 / \mathrm{mm}^{2}$.

A trepanação do doador foi de $8,0 \mathrm{~mm}$ e do receptor de $7,50 \mathrm{~mm}$, sendo ambas sem intercorrências. Ao suturar a córnea, observou-se que a córnea doadora tinha uma lamela que se movimentava em sua base. A dificuldade cirúrgica ocorreu ao dar os pontos, tentando transfixar a parte posterior da córnea sem que o "flap" se deslocasse de sua posição de origem.

O paciente evoluiu sem intercorrências tendo sido alertado, logo após a cirurgia, sobre a possibilidade de realizar um novo transplante devido ao fato da córnea doadora ter sido submetida a LASIK anteriormente. Seis meses após o procedimento, o paciente apresentou um botão transparente, com acuidade visual de 20/40 $(0,5)$ com a seguinte correção: $-0,75$ $-3,75 \times 75^{\circ}$ e ceratometria de 42,57 a $20^{\circ}$ x 46,76 a $80^{\circ}$. O potencial de acuidade visual máxima (PAM) era de 20/40, caracterizando ambliopia no OE. Não houve problemas com a cicatrização. Houve crescimento de epitélio na interface do "flap" no 1ํㅡês pós-operatório, sem progressão até o momento (Figura 1), dispensando reintervenções cirúrgicas.

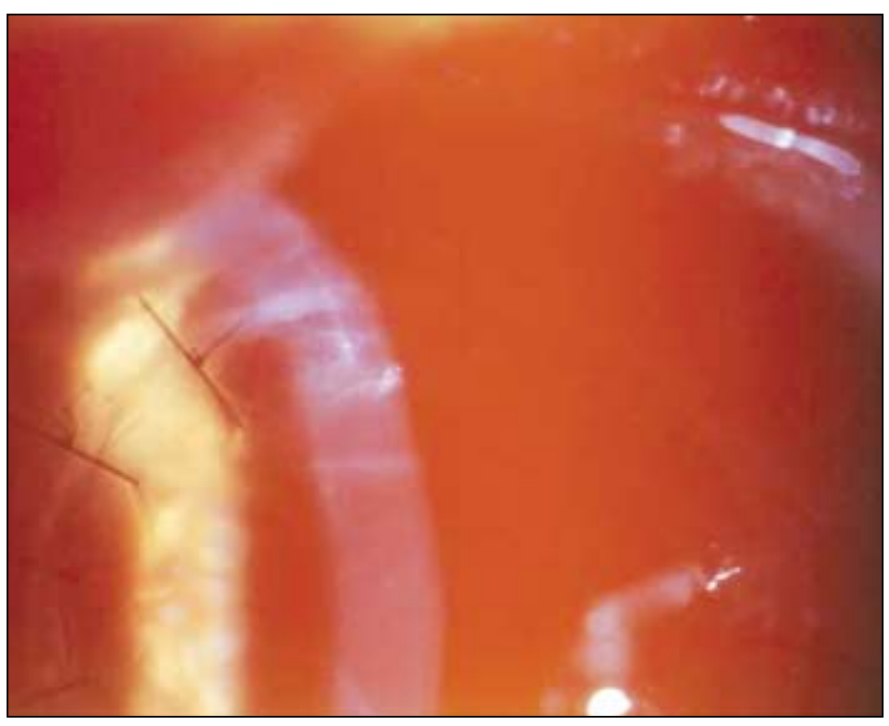

Figura 1 - 1ำ mês de pós-operatório
O exame de ORBSCAN ${ }^{\circledR}$ de 4 e 5 meses após a cirurgia apresentaram resultados semelhantes: o mapa de elevação anterior apresentava elevação irregular; o mapa de curvatura posterior mostrou perda da convexidade posterior da córnea; o mapa topográfico evidenciou astigmatismo irregular e a paquimetria apresentou medida central de 372 micra (Figura 2). Esta medida não coincidiu com a paquimetria manual que era na sua parte central de 461 micra.

Após análise do prontuário oftalmológico do doador, havia registros de que ele tinha sido submetido à cirurgia de LASIK no olho direito para correção de -2,00 DE onze meses antes de falecer (Figura 3). Os parâmetros utilizados para ablação foram: diâmetro da zona óptica de $5,50 \mathrm{~mm}$, profundidade de ablação de $31,8 \mu \mathrm{m}$ e plataforma de $160 \mu \mathrm{m}$. O olho esquerdo apresentava $-0,75 \mathrm{DE}$ e não foi corrigido. A paquimetria do olho direito era de 528 micra.

\section{DISCUSSÃO}

Esta é a primeira descrição de utilização inadvertida de córnea de doador submetido a LASIK em transplante penetrante de córnea no Brasil.

Córneas doadoras passam por testes criteriosos nos Bancos de Olhos para rastreamento de doenças ou condições que contra-indiquem suas utilizações para transplante penetrante $^{(3)}$. Cirurgias corneanas, inclusive cirurgia refrativa são contra-indicações para transplantes penetrantes, ainda que em 1999 uma modificação tenha sido feita no EBAA (Eye Bank Association of America) para permitir sua utilização para transplantes tectônicos( ${ }^{(5)}$. No Brasil, a Agência Nacional de Vigilância Sanitária segundo termos da resolução da diretoria colegiada (RDC 347) estabelece que são contra-indicações relativas a doações de córneas: doadores que tenham sido submetidos à cirurgia intra-ocular ou do segmento anterior; procedimentos refrativos corneanos e fotoablação por laser ${ }^{(6)}$.

Os métodos atuais para rastrear cirurgias ou doenças corneanas nos Bancos de Olhos incluem: biomicroscopia do botão

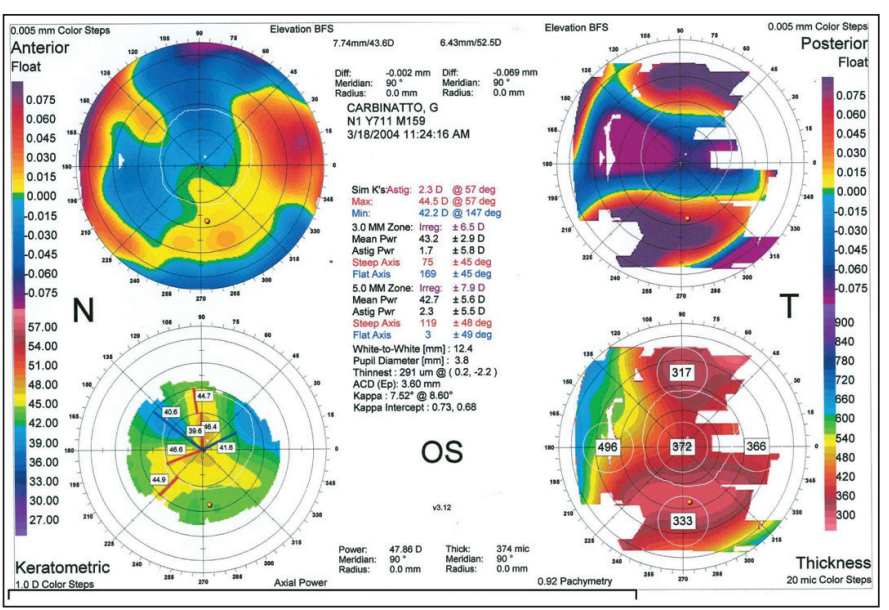

Figura 2 - ORBSCAN ${ }^{\oplus}$ do $5^{\circ}$ mês pós transplante 


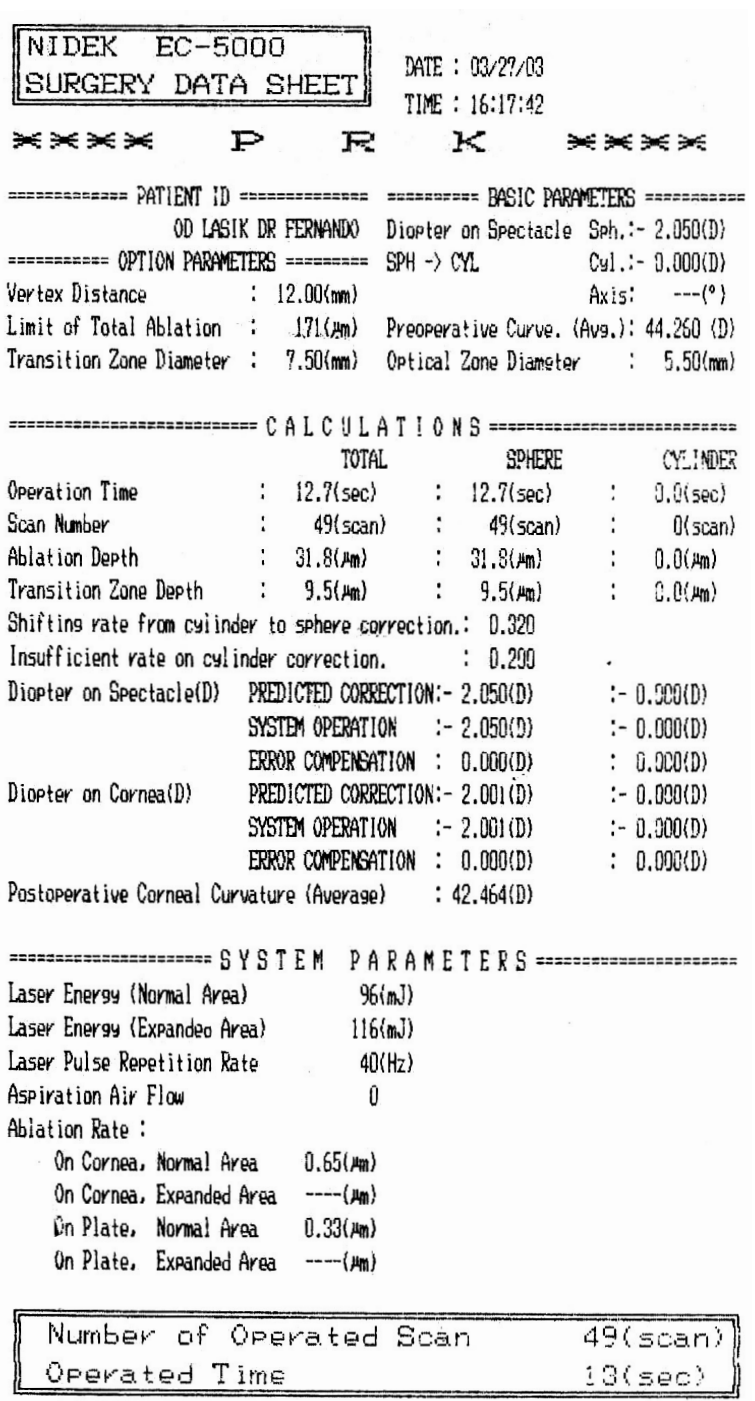

Laser Exciter Vo] tage : $26.4(\mathrm{~kW})[\mathrm{iq})$

Copyright(W)! $992-1998$ NIDEX Co. Lttd. All rights reserved.

Ver. $2.25 \mathrm{dkC}$ Dec, $01,98$.

Figura 3 - Dados do LASIK do doador

à lâmpada de fenda, microscopia especular e entrevista com os parentes mais próximos do doador questionando sobre cirurgias ou doenças prévias ${ }^{(7)}$. Infelizmente, uma história médica negativa fornecida por familiares não é garantia de que o doador esteja livre de alguma doença corneana ${ }^{(7)}$. E, como depois de algum tempo de cirurgia refrativa, é comum não se perceber alterações corneanas, não descartamos neste caso, que o médico examinador da córnea doadora não tenha percebido nenhum sinal de cirurgia refrativa na avaliação pós-mortem.

Cirurgias refrativas induzem mudanças na curvatura, espessura, forma, estrutura e composição bioquímica da córnea ${ }^{(8)}$. Além disso, córneas doadoras que tenham sido previamente submetidas à cirurgia refrativa para correção de miopia podem induzir hipermetropia substancial e irregularidades de superfície no olho receptor resultando em astigmatismo irregular e acuidade visual final baixa ${ }^{(9)}$. No paciente relatado não foi encontrada uma acuidade visual final baixa, pois com uma refração de $-0,75-3,75 \times 75^{\circ}$, o paciente chegou a uma visão de $20 / 40$, sendo o seu PAM de 20/40, o que caracterizou uma ambliopia do OE. Entretanto, o mesmo apresenta um astigmatismo irregular, devendo-se considerar que no 60 mês pós-operatório ainda não foram retirados todos os pontos, os quais só serão completamente retirados com 1 ano de cirurgia.

Alguns grupos, em trabalho ainda experimental, testam a topografia corneana e mapas de paquimetria do ORBSCAN ${ }^{\circledR}$ para rastrear cirurgia refrativa prévia ${ }^{(10)}$. Outros utilizam a videoceratografia computadorizada com o mesmo fim ${ }^{(9)}$.

O ORBSCAN ${ }^{\circledR}$ do paciente, apresentou uma paquimetria muito baixa comparada com a manual. Talvez, o ORBSCAN ${ }^{\circledR}$ tenha medido a espessura corneana a partir de uma das lamelas. Para o ORBSCAN ${ }^{\circledR}$, "haze" com baixa de visão - uma vez que modifica as condições de medida - pode contribuir para resultados hipoestimados indicando uma córnea como sendo muito fina ${ }^{(11)}$. Isto é verdadeiro após ceratite e após ceratectomia fototerapêutica com formação de cicatriz pós-operatória ${ }^{(11)}$.

Durante o procedimento cirúrgico, a tentativa de manter em posição as duas lamelas, pode requerer suturas mais apertadas, o que pode afetar a refração final. E, se as duas lamelas ficarem desalinhadas, poderá produzir aberrações ópticas e interferência com a transparência do botão ${ }^{(4)}$. $\mathrm{O}$ caso descrito apresenta botão transparente até o $6^{0}$ mês pós-operatório.

Após a cirurgia, poderá haver retardos de cicatrização caso a sutura não transfixe as duas lamelas. Tal problema não ocorreu neste caso, nem nos relatados por $\mathrm{Michaeli}^{(4)}$.

Espera-se que apesar da córnea ter sido submetida a LASIK, isto não afete a sobrevivência do transplante, tendo em vista que em teoria, a contagem de células endoteliais é a mesma numa córnea submetida a LASIK ou não ${ }^{(3,12-13)}$.

Embora o paciente esteja satisfeito no 6으 mês pós-operatório com visão de 20/40 com correção, um estudo a longo prazo é necessário para descartar potenciais erros refrativos e falência do botão a longo prazo. O paciente descrito foi informado sobre o incidente com sua córnea doadora e, considera-se sob o aspecto médico-legal, que todos os pacientes devam tomar conhecimento de possíveis intercorrências cirúrgicas durante o transplante ou qualquer outra cirurgia.

Tal incidente deve alertar os Bancos de Olhos para a criação de métodos de rastreamento de cirurgia refrativa em córneas doadoras, uma vez que o número de procedimentos refrativos aumenta a cada dia.

\section{ABSTRACT}

Report on a successful clinical case of a corneal penetrating keratoplasty using inadvertently a corneal graft that had undergone laser assisted in situ keratomileusis (LASIK). Review of a clinical case of a patient of the Cornea Department of the "Hospital Oftalmológico de Sorocaba" who underwent a penetrating keratoplasty (PK) to correct keratoconus in his left 
eye. A corneal graft from a donor who had LASIK surgery was used. Surgery was completed without complications, although a separation of the corneal lamellae was noted during surgery. Patient evolution was good with a final corrected visual acuity of 20/40. PAM was also 20/40. Epithelial growth was noticed on the flap interface, although, without progression of this finding. Eye Banks should improve screening techniques to rule out refractive surgery in the donor corneas; there was no impairment of the final result of this transplant until the $6^{\text {th }}$ month after surgery; long-term follow-up is necessary to reveal if surgical success was impaired by prior refractive surgery.

Keywords: Keratoplasty, penetrating; Keratoconus/surgery; Corneal transplantation; Refraction, ocular; Laser surgery; Case report [Publication type]

\section{REFERÊNCIAS}

1. Datasus: Dados sobre transplante de córnea. [sítio na Internet]. Brasília: Ministério da Saúde. Rede Nacional de Informação em Saúde: 2002. Disponível em URL: http://www.datasus.gov.br.
2. Victor G, Diniz CH, Nosé W. Considerações econômicas da cirurgia refrativa. In: Alves MR, Chamon W, Nosé W editors. Cirurgia refrativa. Rio de Janeiro: Cultura Médica; 2003. p.500-11.

3. Kent DG, Solomon KD, Peng Q, Whiteside SB, Brown SJ, Apple DJ. Effect of surface photorefractive keratectomy and laser in situ keratomileusis on the corneal endothelium. J Cataract Refract Surg. 1997;23(3):386-97.

4. Michaeli-Cohen A, Lambert AC, Coloma F, Rootman DS. Two cases of a penetrating keratoplasty with tissue from a donor who had undergone LASIK surgery. Córnea. 2002;21(1):111-3.

5. Eye Bank Association of America. Medical standards \& procedures materials. Washington: EBAA; 2000. p.8-10.

6. Agência Nacional de Vigilância Sanitária. Resolução da diretoria colegiada no 347. Dezembro 2003.

7. Terry MA, Ousley PJ, Rich LF, Wilson DJ. Evaluation of prior photorefractive keratectomy in donor tissue. Cornea. 1999;18(3):353-8.

8. Pepose JS, Lim-Bon-Siong R, Mardellil P. Future shock: the long-term consequences of refractive surgery. Br J Ophthalmol. 1997;81(6):428-9.

9. Lim-Bon-Siong R, Williams JM, Samapunphong S, Chuck RS, Pepose JS. Screening of myopic photorefractive keratectomy in eye bank eyes by computerized videokeratography. Arch Ophthalmol. 1998;116(5):617-23.

10. Terry MA, Ousley PJ. New screening methods for donor eye-bank eyes. Cornea. 1999;18(4):430-46.

11. Giessler S, Duncker GI. Orbscan pachymetry after LASIK is not reliable. J Refract Surg. 2001;17(3):385-7.

12. Jones SS, Azar RG, Cristol SM, Geroski DH, Waring GO $3^{\text {rd }}$, Stulting RD, et al. Effects of laser in situ keratomileusis (LASIK) on the corneal endothelium. Am J Ophthalmol. 1998;125(4):465-71.

13. Perez-Santonja JJ, Sakla HF, Gobbi F, Alio JL. Corneal endothelial changes after laser in situ keratomileusis. J Cataract Refract Surg. 1997;23(2):177-83. 